\title{
Analysis of the feasibility and necessity of special road construction for small passenger cars
}

\author{
Jin He, Pengfei Chang, and Yanjie Sun* \\ Shanxi Luheng Communications Survey and Design Co., Ltd., Taiyuan 030006, China
}

\begin{abstract}
The rapid development of social economy has caused many problems in highway transportation. The traffic on most roads is getting bigger and bigger. This trend not only increases traffic pressure but also poses a threat to the lives of travellers. In order to solve the current road traffic problem, this paper proposes a special route for the construction of small passenger vehicles. The basic idea of dedicated line construction is based on the secondary road and highway operation forms. Each line passes through 1 to 3 townships. The internal and external environment and advantages and disadvantages of the dedicated line construction were analyzed by SWOT method, and the SWOT matrix was constructed. The analysis results show that the small passenger dedicated line is feasible and necessary, and has a good development prospect. In this way, it provides a new idea for the development of China's highways.
\end{abstract}

\section{Background}

With the rapid development of the market economy and the acceleration of the urban-rural integration process, China's transportation industry has made great progress. According to domestic and international research[1-3], mixed traffic has become an accident-prone area. Yan Shoujing[4] learned through gray correlation analysis that vehicle types are the most important factor in traffic accidents, and mixed traffic is an important source of fatal accidents[5]; Liang Guohua[6] Large vehicle mix rate and traffic stability The relationship is analyzed. The analysis shows that the higher the mixing rate of large vehicles, the worse the traffic stability. At the same time, Yang Jian[7] shows that on the straight road section, the speed of small cars decreases linearly with the increase of truck mixing rate. And with the increase of traffic volume, the "mobile bottleneck" effect is gradually becoming serious; Yang Zijie[8] applied evolutionary game theory to conclude that the game process of largescale driver and small-car driver group belongs to asymmetric game, so In large-scale vehicles, the phenomenon of car pressing on small cars is more serious. .

This paper proposes a construction idea for a special route for small passenger vehicles, aiming to improve the operating speed and safety of highway traffic. It is used to provide new ideas for the development direction and construction of highway traffic engineering in China.

\footnotetext{
* Corresponding author: 747720426@qq.com
} 


\section{Basic assumptions and research methods}

\subsection{Basic assumptions}

According to the yearbook of the length of China's sub-regional transportation routes, the total length of highways in China is $130,973 \mathrm{~km}$ at the end of 2018 . The secondary road is a type of highway grade in China. It is used after the first-class highway and before the thirdgrade highway. It is widely used in the actual road construction. Therefore, the small passenger car road is based on the secondary road. Special roads use the highway mode throughout the journey, but do not charge for passing vehicles. In order to radiate more areas, special roads require 1 to 3 townships. The main route modes are "city-county" and "county-county". Dedicated roads are designed for small cars, with dual lanes and no other vehicles. The dedicated lanes are funded by the state and local governments. The traffic network of the special line in different periods is shown in figure 1.

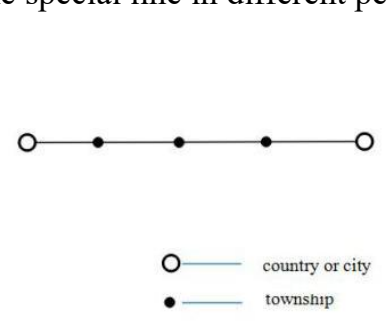

(a)

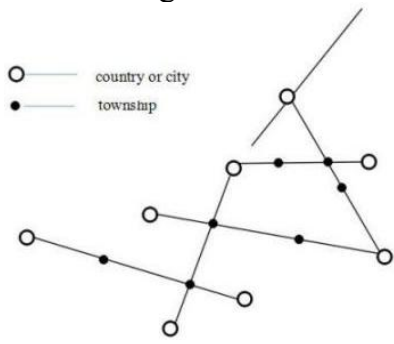

(b)

Fig. 1. Specialized transportation network conditions in different development periods: a. early development; $b$. late development.

\subsection{Research methods}

The SWOT is a qualitative analysis method. It has the advantages of comprehensiveness, system, accuracy and conciseness. It can be used in various development strategies, plans and decision-making, etc. The factors are divided according to the internal and external influence relationship, then enumerate the various factors in the form of matrix, and use the system idea to cross-combine the above various factors to obtain decision-making conclusions. This paper establishes SWOT analysis matrix for the internal and external factors affecting the construction of small passenger car lines, and uses SWOT analysis method to analyze the rationality, necessity and construction ideas of the construction of small passenger car line.

\section{SWOT analysis of dedicated lines}

\subsection{Advantage Analysis (S)}

According to the idea of the small passenger car line in this paper, it has the characteristics of rapidity and flexibility in transportation, has economical in the construction process, and has safety in the driving process.

\subsubsection{Rapidity}

The design speed of the small passenger car line is $80 \sim 120 \mathrm{~km} / \mathrm{h}$, and the total length of the special line is not more than $80 \mathrm{~km}$. The expressway mode (no charge) is used and only small passenger cars are allowed to drive. Objectively speaking, it avoids the phenomenon 
of car pressing caused by the asymmetric game of large and small vehicles. Subjectively, it slows down the driving pressure of small passenger car drivers under mixed traffic and speeds up the driving speed of small passenger cars.

\subsubsection{Economics}

The special line is built on the secondary road construction standard and adopts the expressway operation mode (free of charge). It has reached the operating standard of the expressway in terms of speed, but the construction cost is the construction standard of the secondary road. At the same time, because the special line prohibits the operation of large vehicles, the damage to the road caused by traffic operations is alleviated, and the service life of the road is prolonged.

\subsubsection{Flexibility}

The special line setting is mainly for the "city-county" and "county-county" cases, and passes through 1 3 townships. In the central and eastern regions of China, the population density is relatively large, and the distance between city-county-town is short. Many special lines can form a large transportation network, making transportation flexible and convenient.

\subsubsection{Security}

In the process of transportation, the speed of various vehicles is not the same due to the difference between the models of large and small vehicles. When the traffic volume is large, it is difficult to overtake, which often causes the phenomenon of rolling and hinders the driving speed of the driving. According to the research results of Yang Yao[9], it can be known that the minimum safe car spacing of small cars is smaller than the minimum safe car spacing of large and small cars, which proves that the traffic safety situation of small passenger car lines is better than mixed traffic safety under the same driving conditions. The situation is better, at the same time alleviating the operational pressure of local traffic.

\subsection{Disadvantage Analysis (W)}

The idea of the small passenger car line is based on the secondary road construction standards and the highway operation mode (free of charge), and the radiation range is large in areas with large population density. Therefore, its existence has certain problems such as difficulty in funding sources, difficulty in operation and management, and limitation of radiation range.

\subsubsection{Difficulties in funding}

The dedicated lanes are funded by the state and local governments. The national capital contribution ratio is $30 \%$, and $70 \%$ of the capital is invested by the county. Due to the uneven development of various regions in China and the different regional geological and topographical conditions and people's education level, the attitudes and construction costs of the small passenger car line are different, and the source of funds in the more difficult areas will be more difficult. 
As the entire line prohibits the entry of vehicles other than small passenger vehicles, the entire line is free of charge in order to save the economy. There is no special guard at both ends of the line, so there will be other vehicles mixed into the special line, which will bring inconvenience to traffic operation.

\subsection{Opportunity Analysis (0)}

\subsubsection{Development of artificial intelligence}

At present, China's expressways have two types of charging methods: manual bayonet and ETC. ETC is currently the most advanced road and bridge charging method in the world. Through the microwave-specific short-range communication between the on-board electronic tag, the computer network technology is used to perform background settlement processing with the bank, so that the vehicle does not need to pass through the road and bridge toll station. Parking can pay the road and bridge fees.

\subsubsection{Construction of the "New Silk Road Economic Belt"}

In September 2013, Chinese President Xi Jinping proposed the strategic concept of building the "New Silk Road Economic Belt". On March 28, 2015, the National Development and Reform Commission, the Ministry of Foreign Affairs, and the Ministry of Commerce jointly issued the "Vision and Action for Promoting the Construction of the Silk Road Economic Belt" and "the 21st Century Maritime Silk Road". The "New Silk Road Economic Belt" takes Xi'an as the starting point, and passes through Gansu and Xinjiang to countries along the route, radiating the western region of China, and bringing opportunities for the development of the western region of China. At the same time, it will definitely increase the development of transportation lines in the western region.

\subsection{Threat Analysis ( $T$ )}

\subsubsection{Competition in other modes of transportation}

The route proposed in this paper is exclusive to small passenger transport. The main purpose is to carry out rapid transportation between "city-county" and "county-county" in a short period of time, and alleviate local traffic pressure. At present, when the road is short, the modes of travel are mainly ordinary road transport, highway transport, ordinary rail transport, high-speed rail transport and waterway transport. These modes of travel are mature and accepted by the system. Compared with small passenger lines, high-speed rail transport has a faster running speed, and the expressway has formed a developed transportation network. In the early stage of the dedicated line operation, high-speed rail transportation and highways and transportation will pose serious threats to small passenger lines.

\subsubsection{Imperfections in the legal system}

For the small car passenger dedicated line, it is only the envisaged stage. Due to the construction of the expressway and the ordinary secondary road, the problems that exist in the private line cannot be fully considered. The imperfection of the private line legal system makes it appear that there are more traffic problems during the operation. 


\section{Strategic choice of dedicated line solutions}

The SWOT matrix is used to combine the analysis results into SO, WO, ST and WT strategies. The results are shown in table 1.

Table 1. SWOT matrix of small passenger dedicated line.

\begin{tabular}{|c|c|c|}
\hline & $\mathbf{S}$ & $\mathbf{W}$ \\
\hline \multirow[b]{2}{*}{ O } & SO & WO \\
\hline & $\begin{array}{l}\text { SO1: Taking the national policy as an opportunity } \\
\text { to accelerate the construction of small passenger } \\
\text { dedicated lines and establish a perfect } \\
\text { transportation network; } \\
\text { SO2: Use artificial intelligence to improve the } \\
\text { research and development of new technologies } \\
\text { and new technologies for the construction of } \\
\text { dedicated lines, and seize the market; } \\
\text { SO3: With the national strategy as the background } \\
\text { and the economic and safety of the small } \\
\text { passenger dedicated line, the publicity of the } \\
\text { special line construction will be strengthened. }\end{array}$ & $\begin{array}{l}\text { WO1: expanding the radiation range of } \\
\text { the dedicated transportation network; } \\
\text { WO2: Increase the source of funds for } \\
\text { the construction of special lines in the } \\
\text { context of national policies; } \\
\text { WO3: Utilize the rapid development of } \\
\text { artificial intelligence to improve the } \\
\text { operation mechanism of the dedicated } \\
\text { line. }\end{array}$ \\
\hline & ST & WT \\
\hline $\mathbf{T}$ & $\begin{array}{l}\text { ST1: Development of multimodal transport; } \\
\text { ST2: Develop an operation mechanism with } \\
\text { unique characteristics of small passenger lines; } \\
\text { ST3: Learn from other road transportation } \\
\text { experiences to improve the laws and regulations } \\
\text { for the operation of the special line. }\end{array}$ & $\begin{array}{l}\text { WT1: Improve the construction of } \\
\text { special line laws and strengthen the } \\
\text { operation control of special lines; } \\
\text { WT2: Increase the funding source of } \\
\text { the dedicated line construction and } \\
\text { increase the radiation range of the } \\
\text { special line transportation network; } \\
\text { WT3: Specially designed for small } \\
\text { passenger vehicles to improve the } \\
\text { competitiveness of the dedicated line. }\end{array}$ \\
\hline
\end{tabular}

\subsection{Advantage Opportunity Strategy (SO Strategy)}

For the small passenger dedicated line, combined with its own internal advantages and the use of external opportunities, it can be divided into 3 advantages opportunity strategy.

(1) Taking the national policy as an opportunity, such as the construction of the "New Silk Road Economic Belt", the "Western Development" and the "Rise of the Midwest", etc., using the national preferential policies to vigorously develop the special line construction, and it is easy to use the special line construction engineering experience. Quickly establish a relatively complete dedicated line operation network with reference to the characteristics of short construction period and short construction period, which makes the special line more flexible and flexible in the operation process;

(2) Using artificial intelligence to develop new technologies and new technologies for the construction of dedicated lines on the basis of the original road construction, making it easier to serve traffic and help to seize the transportation market;

(3) Taking the national strategy as the background and combining the economics and safety of the small passenger dedicated line, increase the publicity of the special line construction and increase the competitiveness of the special line.

\subsection{Inferior Opportunity Strategy (WO Strategy)}


Taking advantage of external opportunities and overcoming internal disadvantages, there are mainly 3 inferior opportunity strategies for the construction of China's small passenger dedicated lines.

(1) Expand the radiation range of the dedicated transportation network. Taking the construction of the "New Silk Road Economic Belt" as an opportunity to vigorously promote the construction of special lines in the western and underdeveloped areas, and relying on the development of urban and rural integration to accelerate the penetration of small passenger lines between urban and rural areas. Increase the radiation range of the small passenger dedicated line in the country, and give full play to the speed and flexibility of the dedicated line;

(2) Increase the source of funds for the construction of special lines in the context of national policies. In the context of national policy, such as the construction of the "New Silk Road Economic Belt", the "Western Development" and the "Rise of the Midwest", the region's economic development will be driven, including tourism, agriculture and industry. Economic development will certainly have a large number of transportation line construction needs. For the local economic development, local enterprises and tourism operators will increase their willingness to build transportation routes and enhance the local special line construction financing;

(3) Utilize the rapid development of artificial intelligence to improve the operation mechanism of the dedicated line. With the rapid development of artificial intelligence, new technologies such as face recognition, ETC toll channel and two-dimensional code recognition have emerged. The dedicated line can use ETC channel technology (but free of charge) for vehicle control. Or use techniques such as face recognition and two-dimensional code recognition to control the passing vehicles.

\subsection{Advantage Threat Strategy (ST Strategy)}

While exerting internal advantages and avoiding external threats, there are mainly 3 dominant threat strategies for China's small passenger dedicated lines.

(1) Develop multimodal transport. Small passenger transport lines are not as transportable as rail and water transport, and are not as fast as air transport. However, on a shorter distance, the special line can guarantee fast transportation and free of charge to make up for the shortage of other modes of transportation. Therefore, the small passenger dedicated line can be combined with other modes of transportation to give full play to the internal advantages of the small passenger line;

(2) Develop an operation mechanism with unique characteristics of small passenger lines. Because of its numerous internal advantages, especially because of its low cost, good security, and the implementation of full-line free system and rapidity, it is a strong advantage. New technologies and new methods must be utilized to enhance these internal strengths and develop operational mechanisms that are unique to small passenger lines;

(3) Learn from other road transportation experiences to improve the laws and regulations for the operation of special lines. Since the small passenger line is a kind of road transportation, in the operation and management of the special line, other laws and regulations on the form of road transportation can be used to restrict the behavior of the vehicle on the special line, and strengthen the control of the special line.

\subsection{Inferior Threat Strategy (WT Strategy)}

In overcoming the internal disadvantages of the small passenger-only route and at the same time avoiding external threats, there are mainly 3 disadvantage threat strategies for small dedicated routes. 
(1) Improve the construction of special line laws and strengthen the operation control of special lines. We will improve the laws and regulations of small passenger lines and restrict driving behaviors to avoid traffic problems caused by inadequate laws and regulations. Sound laws and regulations also constrain the incorporation of other types of mobile and non-motorized vehicles into small passenger-only routes;

(2) Increasing the source of funds for the construction of special lines and increasing the radiation range of the special line transportation network;

(3) Specially serve small passenger vehicles to improve the competitiveness of the special line. Since the dedicated line specializes in small passenger vehicles, it is necessary to establish a corresponding emergency response mechanism for small passenger vehicles to improve the service quality and then increase the competitiveness of the small passenger dedicated line and expand its development scope.

\section{Conclusion}

The SWOT analysis method was used to analyze the construction of special routes for small passenger cars in China. Advantages and disadvantages of the dedicated line were discussed. The SWOT matrix was used to analyze its solution. The main conclusions are as follows:

(1) The internal advantages of dedicated line construction is far greater than the internal disadvantages. It can be solved by analyzing external defects, so the construction of small passenger lines is feasible.

(2) The external opportunity for the construction of the dedicated line is greater than the external threat it receives. External opportunities allow the line to take full advantage of its internal strength while avoiding external threats. so the construction of small passenger lines is necessary.

(3) With the development of national policy background and artificial intelligence, the small passenger transport line has great support in economy and technology. The construction of small passenger transport line will have better development prospects.

\section{References}

1. Fred L. Mannering, Venky Shankar, Chandra R. 2016 Unobserved heterogeneity and the statistical analysis of highway accident data Analytic Methods in Accident Research, vol 11.

2. Young Ai Kim, Boong Yeol Ryoo, Yong-Su Kim, et al. 2013 Major Accident Factors for Effective Safety Management of Highway Construction Projects Journal of Construction Engineering and Management, vol 139.

3. Jonathan C. Comer, Nicholas J. Rose, Leonard S. 2014 Bombom. Poisson Regression Analysis of Highway Fatality Accident Data in Oklahoma International Journal of Applied Geospatial Research (IJAGR), vol 5.

4. Yan Shoujing, Liu Jinghui, Yang Zezhong, et al. 2017 Analysis of urban road traffic accident rate Traffic and Transportation,pp215-218.

5. WANG Jianjun, BI Mingtao. 2004 Research and Countermeasures of Highway Mixed Traffic Problem Highway pp 95-99.

6. LIANG Guo-hua, CHENG Guo-zhu, WANG Chun-yan, et al. 2014 Relationship between the mixed rate of large-scale expressway and traffic flow stability Journal of Chang'an University (Natural Science Edition), vol 34 ,pp 120-126. 
7. Yang Jian.2014 The Influence of Mixed Speed of Low Speed Freight Cars on Small Cars Traffic Standardization, vol 42,pp 73-75.

8. YANG Zijie, JIA Zhizhen. 2014 Evolutionary analysis of the behavior of large and small cars in the traffic bottleneck Journal of Taiyuan University of Science and Technology, vol 35,pp49-53.

9. Yang Yao. 2016 Research on the minimum safe driving distance of expressway Chang'an University. 